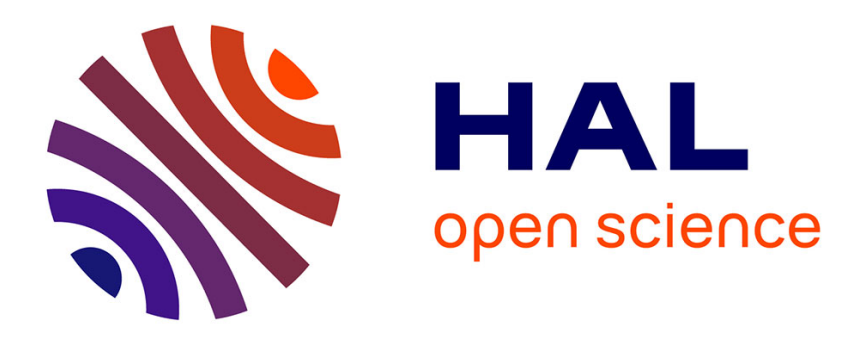

\title{
Pluralizing the Paraphrase: Reconsidering Meaning via a Typology of Linguistic Changes
}

\author{
Miki Mori
}

\section{To cite this version:}

Miki Mori. Pluralizing the Paraphrase: Reconsidering Meaning via a Typology of Linguistic Changes. TESOL Quarterly, 2019, 53 (3), pp.885-895. 10.1002/tesq.514 . hal-02910317

\section{HAL Id: hal-02910317 https://hal.science/hal-02910317}

Submitted on 1 Aug 2020

HAL is a multi-disciplinary open access archive for the deposit and dissemination of scientific research documents, whether they are published or not. The documents may come from teaching and research institutions in France or abroad, or from public or private research centers.
L'archive ouverte pluridisciplinaire HAL, est destinée au dépôt et à la diffusion de documents scientifiques de niveau recherche, publiés ou non, émanant des établissements d'enseignement et de recherche français ou étrangers, des laboratoires publics ou privés. 


\section{Miki Mori (2019) Pluralizing the Paraphrase: Reconsidering Meaning via a Typology of Linguistic Changes, 2019, TESOL Quarterly, 53(3), 885-895.}

\section{DOI: 10.1002/tesq.514}

Miki Mori, Associate Professor of Linguistics CUFR Mayotte mikimorimayotte@gmail.com

For several years, I taught undergraduate writing to international and first and second generation students in the U.S. Like many academic writing classes, one of the pillars of my syllabi concerned the use of outside sources, including internet research, source credibility, plagiarism, and the "triad" (Keck, 2006), which consists of the quotation, the summary and the paraphrase. General consensus agrees development of such skills to be difficult for students, and the process can be better understood and pedagogically improved (Abasi \& Akbari, 2008; Howard, 1999; Howard \& Robillard, 2008, Hutchings, 2014). However, it was the paraphrase that my students struggled with. Some found it difficult to identify an adequate paraphrase, such as whether changing the adverb "patently" to "very" constitutes plagiarism in "It seems very unfair to hold a person liable" from "It seems patently unfair to hold a person liable" (most would agree this is a poor paraphrase). Other students found it difficult to manipulate the language from the source text in order to render it acceptable, such as how to transform the above sentence into "Considering someone responsible appears unjust." This difficulty stemmed not from a lack in lexical repertoire (as thesauri are easily accessible) but a lack of knowledge of the transformations a paraphrase undergoes, in this case lexical and morpho-syntactic changes. At the time, I felt unequipped in helping them unpack this process. My interest in paraphrasing continued as I analyzed student paraphrases during my dissertation research. I was inspired by the work of Shi (2004) and Keck (2014) in which they 
categorize paraphrases along broad categories ${ }^{1}$. However, I wanted to find a more comprehensive classification system to identify linguistic changes made during a paraphrase. In my search for other approaches, I found insight in an unlikely place, computational linguistics, where a typology of changes had been developed. It is this insight that I share in this Teaching Issues article in the hopes that writing teachers may be motivated to apply it in their classes or during action research.

The academic community identifies paraphrasing as a challenging yet important skill (Hirvela \& Du, 2013; Howard, 1992; Keck, 2006; Pecorari \& Shaw, 2012) that demands rhetorical and linguistic considerations. Rhetorical considerations include the use of paraphrasing for argumentation, the role of genre, and intertextuality and dialogism, among other issues (see Hyland, 2000; Mori, 2018; and Swales, 2014). In the context of citation and plagiarism, it has been largely studied with important findings that could be discussed in length ${ }^{2}$ but are beyond the scope of this article (see Bloch, 2012; Howard \& Robillard, 2008; Pecorari, 2006, 2015; and the Journal of Second Language Writing's December 2015 “Disciplinary Dialogues”). Nevertheless, writing instructors are tasked with teaching source use while providing ways for students to avoid plagiarism, often by paraphrasing. Paraphrase research has focused on the complex nature of source incorporation, including looking at conventional and unconventional (Pecorari \& Shaw, 2012) or transgressive versus nonstransgressive types of source use (Chandrasoma, Thompson, \& Pennycook, 2004), and giving attention to student and professor's perspectives on effective paraphrases versus patchwriting (Li \& Casanave, 2012; Roig, 1997; Roig, 2001; Shi, 2012). Studies have focused on paraphrasing as related to summaries (Keck, 2014; Shi, 2012) and quotation (Petrić, 2012). Importantly, research has shown that second language writers struggle with source use and

\footnotetext{
${ }^{1}$ Shi's (2004) analysis categorized a paraphrase as copied, slightly modified or syntactically reformulated. Keck's (2014) taxonomy included a near copy, minimal revision, moderate revision and substantial revision. ${ }^{2}$ Although often linked to plagiarism, paraphrasing is not the lack of plagiarism. Generally speaking, plagiarism can be unintentional or deliberate, cited or uncited, but always involves a string of texts copied exactly from a source.
} 
plagiarism (Flowerdew \& Li, 2007; Gu \& Brooks, 2008; Hayes \& Introna, 2005; Hirvela \& Du, 2013; Pecorari, 2003; Pecorari, 2008; Pennycook, 1994). While rhetorical issues can generate problems with plagiarism, it is often the linguistic considerations that challenge students.

\section{(Re)defining paraphrasing}

One of the biggest challenges in teaching the paraphrase is defining what it is. ${ }^{3}$. In general, definitions can be categorized as either a retelling of someone else's words in one's own words or a ratio of copied and original language. The triangle in Figure 1 shows these two approaches at the bottom-left and the apex. First, extensive research has been done on paraphrasing in which it is understood as a reformulation of a source text (see Campbell, 1998; Cimasko, 2013; Hirvela \& Du, 2013; Shi, 2004). This is a useful preliminary approach. Others have approached the paraphrase as a ratio of same to unique words in order to analyze texts through categorization (see Jamieson \& Howard, 2011; Keck, 2006, 2010, 2014). This ratio system has been used to delimit an acceptable paraphrase from an unacceptable one. These approaches can certainly be useful for writing instructors, as they provide various perspectives on understanding how a source can be adapted into a paraphrase. All the same, where rephrasing/reformulating is vague, ratio/percentage remains restrictive in its narrow delineation of paraphrase to plagiarism. The focus of this paper is to elaborate on a third category, a typology of changes, bottom-right. As discussed earlier, previous studies (Keck, 2014; Shi, 2004) expressed the importance of categorizing paraphrases. This third option, allows for specific linguistic features to be identified and quantified. It is this approach that I choose to focus on for the remainder of the paper, in the hopes that it could be adapted by instructors in conjunction with the other approaches in Figure 1.

\section{A typology of linguistic changes}

\footnotetext{
${ }^{3}$ The goal of this article is not to define (in)appropriate paraphrasing, but to offer up an approach that can be used in conjunction with other approaches by teachers when defining the term for their classes.
} 
As it happens, research specifically addressing grammatical features of paraphrases using a schema is found in computational linguistics, in the design of plagiarism-detecting software programs. The nature of creating such a program required Barron-Cedeno, Vila, Martí, and Rosso (2013) and Vila, Martí, and Rodríguez (2014) to develop a detailed typology for categorizing paraphrases according to morphology, lexical features, and syntax (see Barron-Cedeno et. al. 2013 for the full typology). A simplified typology shown in Figures 2 and 3 was created for my research purposes but could also be adapted for classroom purposes. I provide examples from one undergraduate student Wes (a pseudonym) in Table 1 and 2, an advanced English language writer from Hong Kong, in his last year of university. He was a research participant in my dissertation project and was enrolled in a mandatory upper-division writing course.

Starting with morpholexical features (Figure 2), the category distinguishes between changes in morphology versus the lexicon. For morphological changes, analyses look at whether a paraphrase changes the tense of a verb (inflectional) such as went to has gone or a noun transformed into an adjective (derivational) such as happiness to happy. Synthetic/analytic changes concern whether or not suffixes versus separate words are used, such as the possessive $s$ and the phrase $x$ of $y$. Wes' paraphrases included various morpholexical changes (Table 1), some of which proved to be a combination of morphological and lexical adjustments such as examples 4 and 6. His paraphrases demonstrate his ability to manipulate language, suggesting a certain level of linguistic mastery. That is, he appears to successfully paraphrase the sources using morpholexical and structural changes.

For structural changes (Figure 3), syntax and discourse markers can be analyzed, including change in voice from active to passive (diathesis) such as active to passive physical bullying includes vs. physical bullying is defined as and clause reordering, where a compound 
or complex sentence with two clauses reverses the order. Changes in connecting words such as subordinating conjunctions (although, despite, if, because) and conjunctive adverbs (however, nevertheless, thus, furthermore) can also be categorized. Coordination changes pertains to connecting words, such as use of coordinating conjunctions (and, but, so) to change a complex sentence to a compound one or combining simple sentences. Subordination involves any instances where an independent clause becomes dependent, such as it is true to although it is true. For discourse changes, modality, or changing a sentence from declarative to interrogative is an option, as well as changes in punctuation. Wes also manipulated sentence structure, as seen in Table 2, including embedding, voice, and reordering. While considered to be among the weaker students of the class, analyses of his paraphrases suggest strong linguistic skills.

There are several pedagogical and institutional implications in secondary and postsecondary settings for the use of this typology. This typology can be a support tool while teaching source incorporation via paraphrasing. It is something I would have appreciated having when I started out teaching academic writing since it could have provided grounding for categorizing student text. Specifically, the typology of morpholexical features (Figure 2) allows for more detailed analysis beyond simply classifying paraphrases by lexical changes. In addition, considering the typology for structural changes (Figure 3) allows for a more refined approach to understanding syntactic changes in a paraphrase. Depending on the course syllabus and teacher policy, certain linguistic changes may be more valued than others, such as derivational changes over inflectional changes, since they require more complex linguistic manipulation. Subordination modifications may hold more value over punctuation changes because they require students to master syntactical operations and knowledge of subordinating conjunctions. Teachers may want to rank the morpholexical and syntactic manipulations according to importance and require students to carry out a minimal amount of top-ranked 
transformations in order to discourage paraphrases that have simple synonym exchanges or minimal punctuation changes, such as using a semi-colon to combine two sentences. The value and ranking would depend on the instructional goals of the course and institutional policy. In any case, it should be made clear to students which changes hold the most value and why.

Furthermore, the typology could be taught in conjunction with grammar lessons on sentence structure (simple, compound, complex, compound-complex), conjunctions (subordinating and compound), tense (for inflectional morphology) and parts of speech (for derivational morphology) in order to make connections between grammar and its use in writing. Students might see the interest in learning such metalinguistic content because they would be directly applying it when incorporating outside sources. For example, instructors could give an exercise on subordination in which the student must paraphrase one sentence from a source text by subordinating it and attaching it to a main clause with an appropriate subordinating conjunction. A handout of the typology with examples of each type of transformation would be useful for the students to refer to while engaging in certain lessons, such as when discussing word choice, sentence structure, coordinating words, etc. The typology would be presented in a scaffolded manner, making it integrated with the course content. In addition, teachers could encourage students to consider making larger structural and morphological changes first to a paraphrase before deciding on lexical changes.

As for incorporating the triangle (Figure 1) into class lessons, teachers could first discuss the overall concept of paraphrasing as a reformulation (the apex), before introducing the categories for analyzing paraphrases by morphological, lexical, or syntactic changes in order to help give concrete examples of rephrasing (bottom right). Lessons could begin with analyzing sample paraphrases using the typology, starting from simple to complex, such as beginning with synonym changes, then derivational, followed by syntactic changes. Since it is 
possible that students may desire an easy way to gauge their paraphrase as acceptable or not, teachers could then incorporate the ratio analyses as sort of Litmus test to check if their source use is appropriate (bottom left).

For institutional implications, instructors and policy makers may use the typology as a roadmap to guide policy defining (un)acceptable source use. Adopting such a typology may facilitate the work of policy makers and the writing instructors duty-bound to enforce policy. Given clear guidelines, instructors can take time to teach them. Considering Figure 1, policies might want to use a combination of approaches.. For example, a department might adapt the $20 \%$ threshold identified by the Citation Project (or another threshold ratio) with the stipulation that a paraphrase must include a combination of lexical, morphological and syntactic changes according to the typology. Indeed, given the desire for quantification in many institutional settings, a ratio analyses in combination with a typological analyses may be the best compromise. Considerations may also be made to exclude formulaic language seen in original and paraphrased texts (Pecorari, 2008). On the other hand, instructors might prefer to overlook percentages and require a substantial amount of linguistic changes identifiable by the typology.

Last, while it is beyond the scope of this article, changes in semantics and their connection to how paraphrases transform meaning is an important factor to be taken into consideration when teaching paraphrasing (Yamada, 2003). Studies have shown that L2 writers struggle with this aspect of paraphrasing (Gu \& Brooks, 2008; Hirvela \& Du, 2013; Keck, 2010; Lee, 2010; Mei \& Allison, 2005). Various other angles need to be addressed, such as the role of evaluation (also known as stance, Biber, 2006), and the task of interpretation during source incorporation. 


\section{Conclusion}

Just as Howard and Robillard (2008) called for a pluralizing of plagiarism to involve context-specific considerations, paraphrasing as a concept in policy and practice needs to be further understood and scrutinized from a variety of frameworks and contexts, by taking it beyond just one fragment of a triad of options. Educators and researchers may consider ways to test the typology on paraphrased texts and consider what aspects are deemed appropriate in their particular settings and how students respond to it. This typology offers just one additional method aimed to help writing instructors approach the paraphrase. Its purpose is to add onto research (Keck, 2014; Shi, 2004) by allowing for nuanced categorization of linguistic changes to help instructors go beyond teaching the paraphrase as putting a text "in your own words," to encourage school policy makers to better define effective paraphrasing, and ultimately to help students understand what is expected of them. Paraphrasing takes time to master, and a poor paraphrase may indicate that students are engaging in an activity which the academy values and hopes to develop in students. Pecorari (2003) expressed a similar idea, noting, "Today's patch-writer is tomorrow's competent academic writer, given the necessary support to develop" (p. 338). This typology may just be one of the many necessary supports needed for development.

\section{Acknowledgements}

The author would like to thank the anonymous reviewers and the editors for their constructive feedback, which helped in improving this manuscript.

\section{Author bio}

Miki Mori is Associate Professor of Linguistics at the Centre Universitaire de Mayotte, where she teaches linguistics, discourse analysis and English to undergraduate and graduate students. Her research addresses sociolinguistic aspects of language learning and use. She has recently embarked on a project of phonetic descriptions of Mayotte's local languages. 


\section{References}

Abasi, A. R., \& Akbari, N. (2008). Are we encouraging patchwriting? Reconsidering the role of the pedagogical context in ESL student writers' transgressive intertextuality. English for Specific Purposes, 27(3), 267-284. doi: 10.1016/j.esp.2008.02.001

Barron-Cedeno, A., Vila, M., MartÍ, M. A., \& Rosso, P. (2013). Plagiarism meets paraphrasing: insights for the next generation in automatic plagiarism detection. Computational Linguistics, 39(4), 917-947.doi:10.1162/COLI_a_00153

Biber, D. (2006). Stance in spoken and written university registers. Journal of English for Academic Purposes, 5(2), 97-116. doi: 10.1016/j.jeap.2006.05.001

Bloch, J. (2012). Plagiarism, intellectual property and the teaching of L2 writing. Buffalo, New York: Multilingual Matters.

Campbell, C. (1998). Teaching second language writing: Interacting with text. Boston, Massachussetts: Heinle \& Heinle.

Chandrasoma, R., Thompson, C., \& Pennycook, A. (2004). Beyond plagiarism: Transgressive and nontransgressive intertextuality. Journal of Language, Identity \& Education, 3(3), 171-193. doi: 10.1207/s15327701jlie0303_1

Cimasko, T. (2013). The Purdue OWL: Paraphrasing. Retrieved from https://owl.english.purdue.edu/owl/resource/976/02/

Flowerdew, J., \& Li, Y. (2007). Language re-use among Chinese apprentice scientists writing for publication. Applied Linguistics, 28(3), 440-465. doi: 10.1093/applin/amm031

Gu, Q., \& Brooks, J. (2008). Beyond the accusation of plagiarism. System, 36(3), 337-352. doi: 10.1016/j.system.2008.01.004

Hayes, N., \& Introna, L. D. (2005). Cultural values, plagiarism, and fairness: When plagiarism gets in the way of learning. Ethics and Behavior, 15(3), 213-231. 
Hirvela, A. \& Du, Q. (2013). “Why am I paraphrasing?”: undergraduate ESL writers' engagement with source-based academic writing and reading. Journal of English for Academic Purposes, 12(2), 87-98.

Howard, R. M. (1992). A plagiarism pentimento. Journal of Teaching Writing, 11(2), 233245.

Howard, R. M. (1999). Standing in shadow giants: Plagiarists, authors, collaboratoes. Stamford, Connecticut: Ablex Publishing Corporation.

Howard, R. M., \& Robillard, A. E. (Eds.). (2008). Pluralizing plagiarism: Identities, context, pedagogies. Portsmouth, NH: Boynton/Cook.

Hutchings, C. (2014). Referencing and identity, voice and agency: Adult learners' transformations within literacy practices. Higher Education Research \& Development, 33(2), 312-324. doi: 10.1080/07294360.2013.832159

Hyland, K. (2000). Disciplinary discourses: Social interactions in academic writing. New York: Pearson Education.

Jamieson, S. \& Howard, R. M. (2011). "Glossary for paper coding" from the website "The Citation Project: Preventing plagiarism, teaching writing" Retrieved from http://site.citationproject.net/

Keck, C. (2006). The use of paraphrase in summary writing: A comparison of L1 and L2 writers. Journal of Second Language Writing, 15(4), 261-278. doi:

10.1016/j.jslw.2006.09.006

Keck, C. (2010). How do university students attempt to avoid plagiarism? A grammatical analysis of undergraduate paraphrasing strategies. Writing \& Pedagogy, 2(2), 193-222. doi: 10.1558/wap.v2i2.193 
Keck, C. (2014). Copying, paraphrasing, and academic writing development: A reexamination of L1 and L2 summarization practices. Journal of Second Language Writing, 25, 4-22. doi: 10.1016/j.jslw.2014.05.005

Lee, S. H. (2010). Attribution in high- and low-graded persuasive essays by tertiary students. Functions of Language, 17(2), 181-206. doi: 10.1075/fol.17.2.02lee

Li, Y., \& Casanave, C. P. (2012). Two first-year students'strategies for writing from sources: Patchwriting or plagiarism? Journal of Second Language Writing, 21(2), 165-180. doi: 10.1016/j.jslw.2012.03.002

Mei, W. S., \& Allison, D. (2005). Evaluative expressions in analytical arguments: Aspects of appraisal in assigned english language essays. Journal of Applied Linguistics, 2(1), 105-127. doi: 10.1558/jal.v2i1.105

Mori, M. (2018). Our speech is filled with others' words: Understanding university student and instructor opinions towards paraphrasing through a Bakhtinian lens. Ampersand, 5, 45-54. doi: 10.1016/j.amper.2018.11.002

Pecorari, D. (2003). Good and original: Plagiarism and patchwriting in academic secondlanguage writing. Journal of Second Language Writing, 12(4), 317-345. doi: 10.1016/j.jslw.2003.08.004

Pecorari, D. (2006). Visible and occluded citation features in postgraduate second-language writing. English for Specific Purposes, 25(1), 4-29. doi: 10.1016/j.esp.2005.04.004

Pecorari, D. (2015). Plagiarism in second language writing: Is it time to close the case? Journal of Second Language Writing, 30, 94-99. doi: 10.1016/j.jslw.2015.08.003

Pecorari, D., \& Shaw, P. (2012). Types of student intertextuality and faculty attitudes. Journal of Second Language Writing, 21(2), 149-164. doi: 10.1016/j.jslw.2012.03.006

Petrić, B. (2012). Legitimate textual borrowing: Direct quotation in L2 student writing. Journal of Second Language Writing, 21(2), 102-117. doi: 10.1016/j.jslw.2012.03.005 
Roig, M. (1997). Can undergraduate students determine whether text has been plagiarized? The Psychological Record, 47, 113-122. doi: 10.1007/BF03395215

Roig, M. (2001). Plagiarism and paraphrasing criteria of college and university professors. Ethics \& Behavior, 11(3), 307-323. doi: 10.1207/S15327019EB1103_8

Schleppegrell, M. (2004). The language of schooling: A functional linguistics perspective. New Jersey: Lawrence Erlbaum Associates.

Shi, L. (2004). Textual borrowing in second-language writing. Written Communication, 21(2), 171-200. doi: 10.1177/0741088303262846

Shi, L. (2012). Rewriting and paraphrasing source texts in second language writing. Journal of Second Language Writing, 21(2), 134-148. doi: 10.1016/j.jslw.2012.03.003

Swales, J. (2014). Variation in citational practice in a corpus of student biology papers: From parenthetical plonking to intertextual storytelling. Written Communication, 31(1), 118-141. doi: 10.1177/0741088313515166.

Vila, M., Martí, M. A., \& Rodríguez, H. (2014). Is this a paraphrase? What kind? Paraphrase boundaries and typology. Open Journal of Modern Linguistics, 4(1), 205-218. doi: 10.4236/ojml.2014.41016

Yamada, K. (2003). What prevents ESL/EFL writers from avoiding plagiarism?: analyses of 10 North-American college websites. System, 31(2), 247-258. doi: 10.1016/S0346$251 X(03) 00023-X$ 
Figure 1 Triangle of three complementary ways to understand paraphrasing

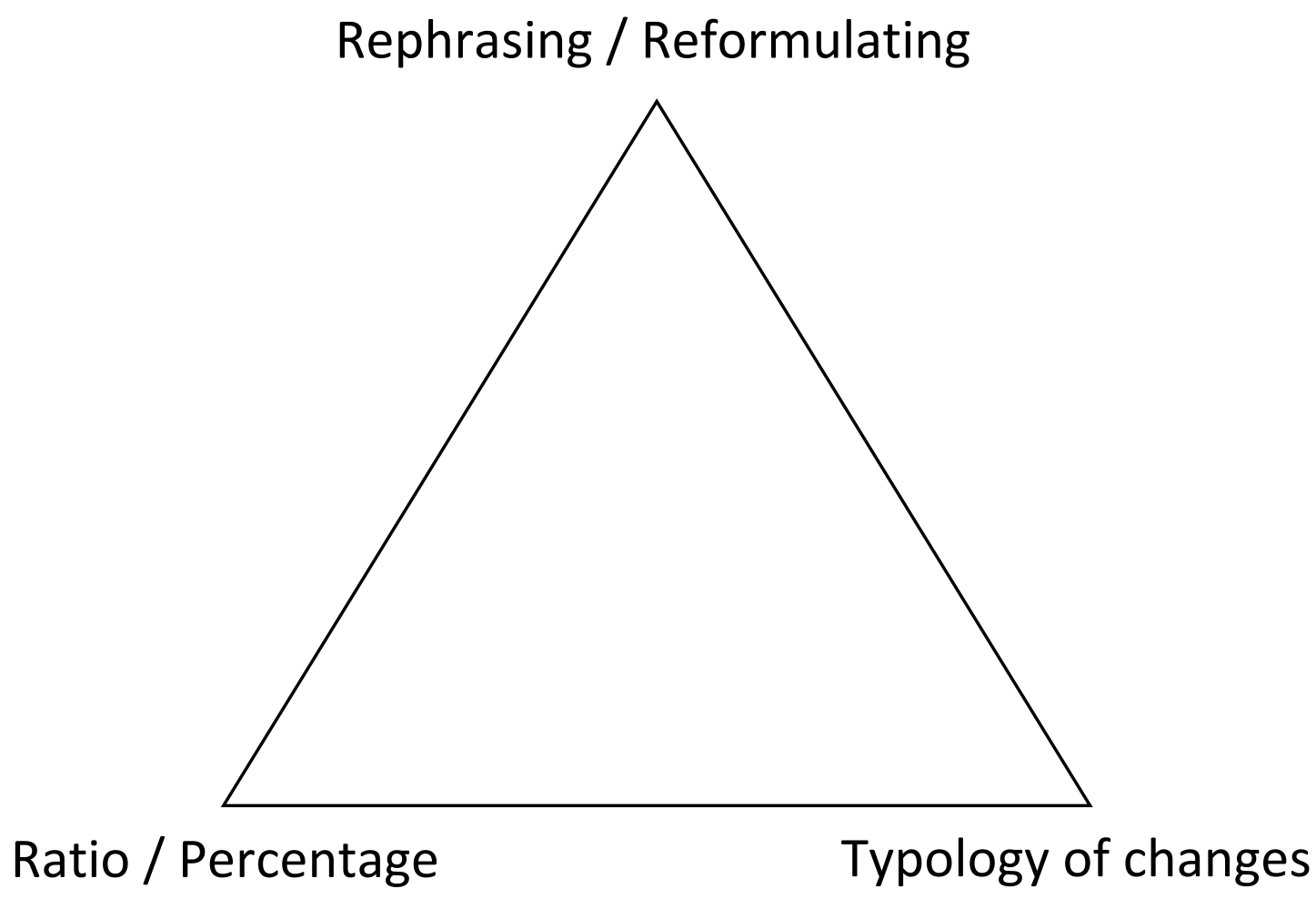


Figure 2 Morpholexical classification: morphology and lexicon

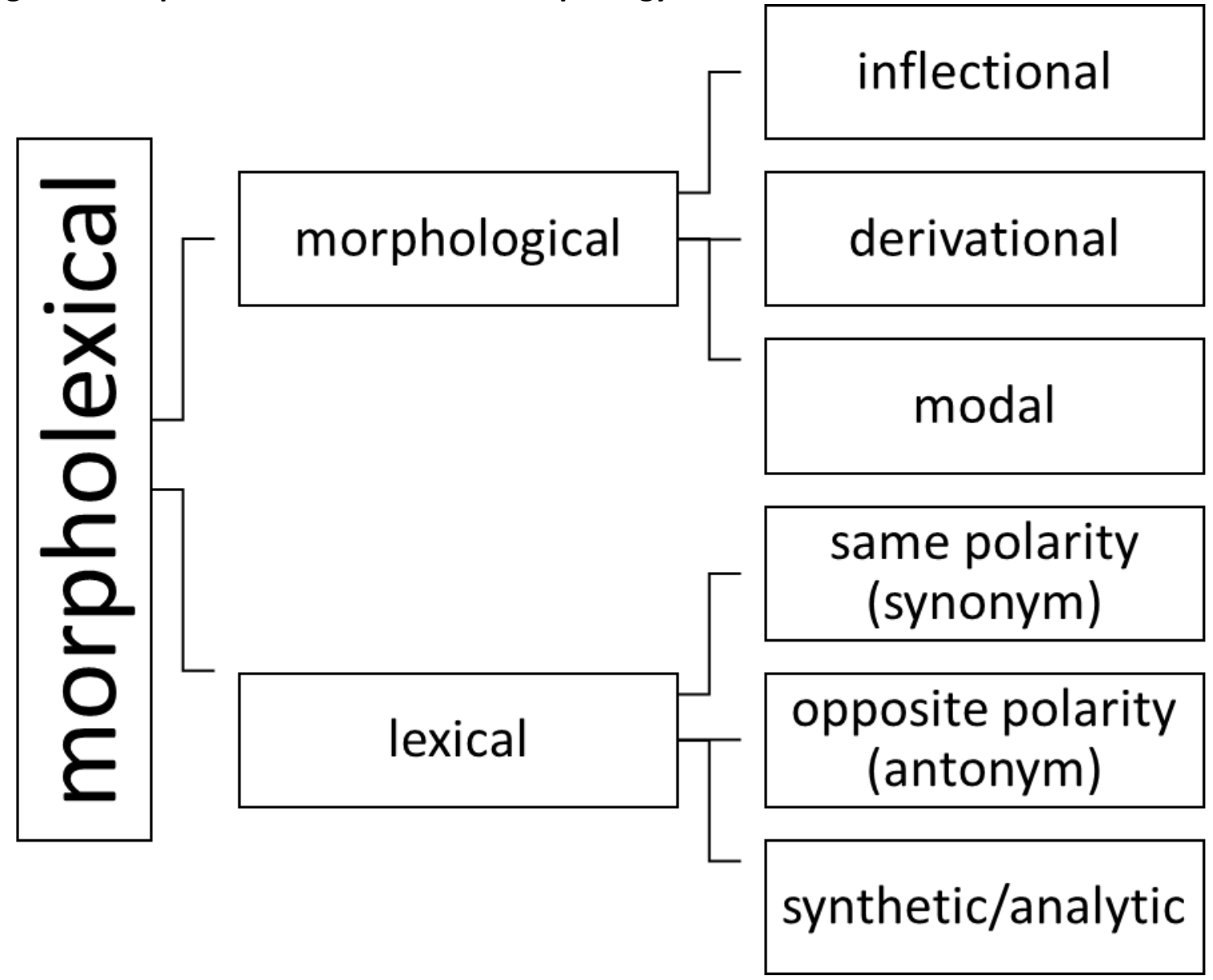


Figure 3 Structural classification: syntax and discourse

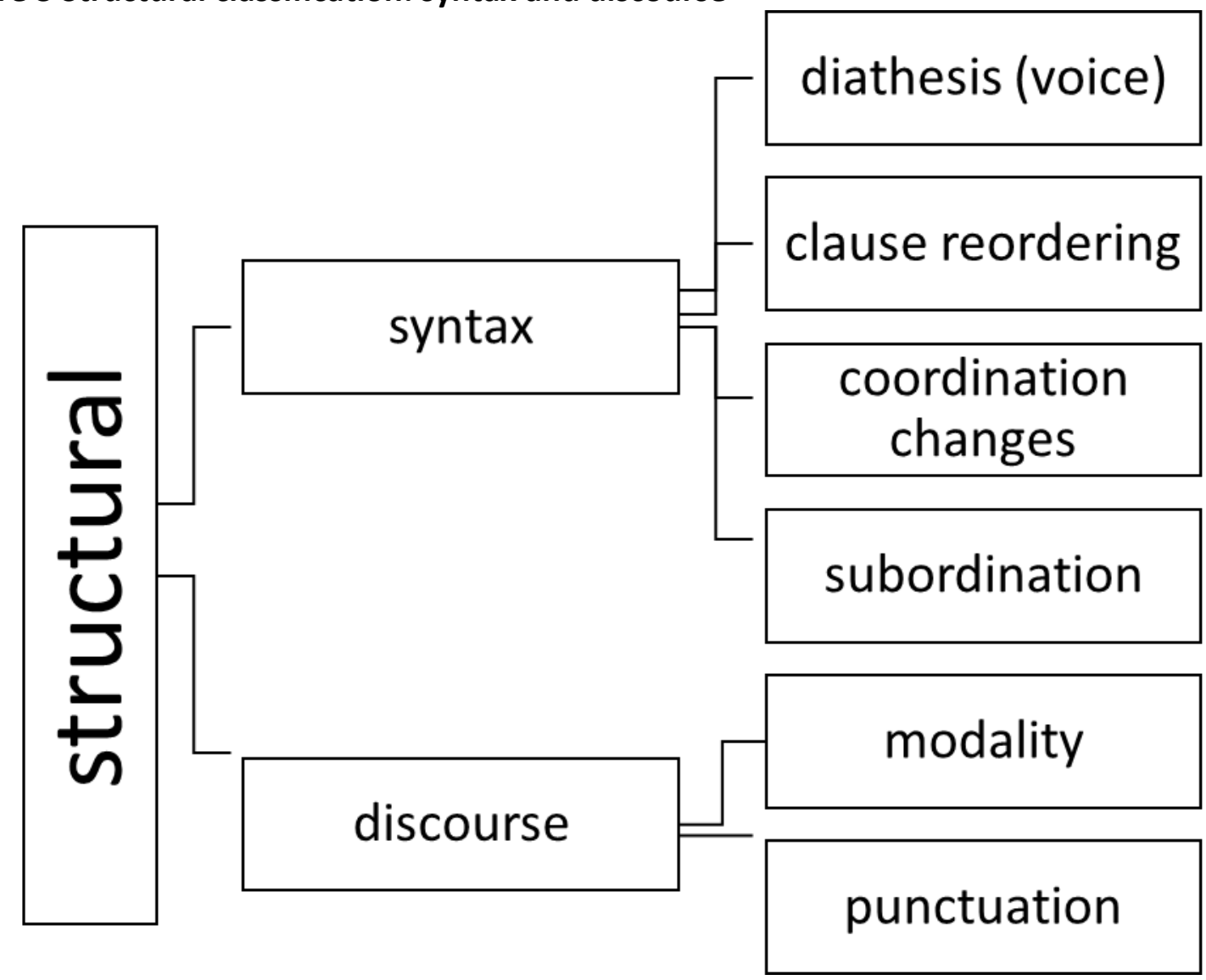


Table 1 Wes' Paraphrases Showing Morphological and Lexical Changes

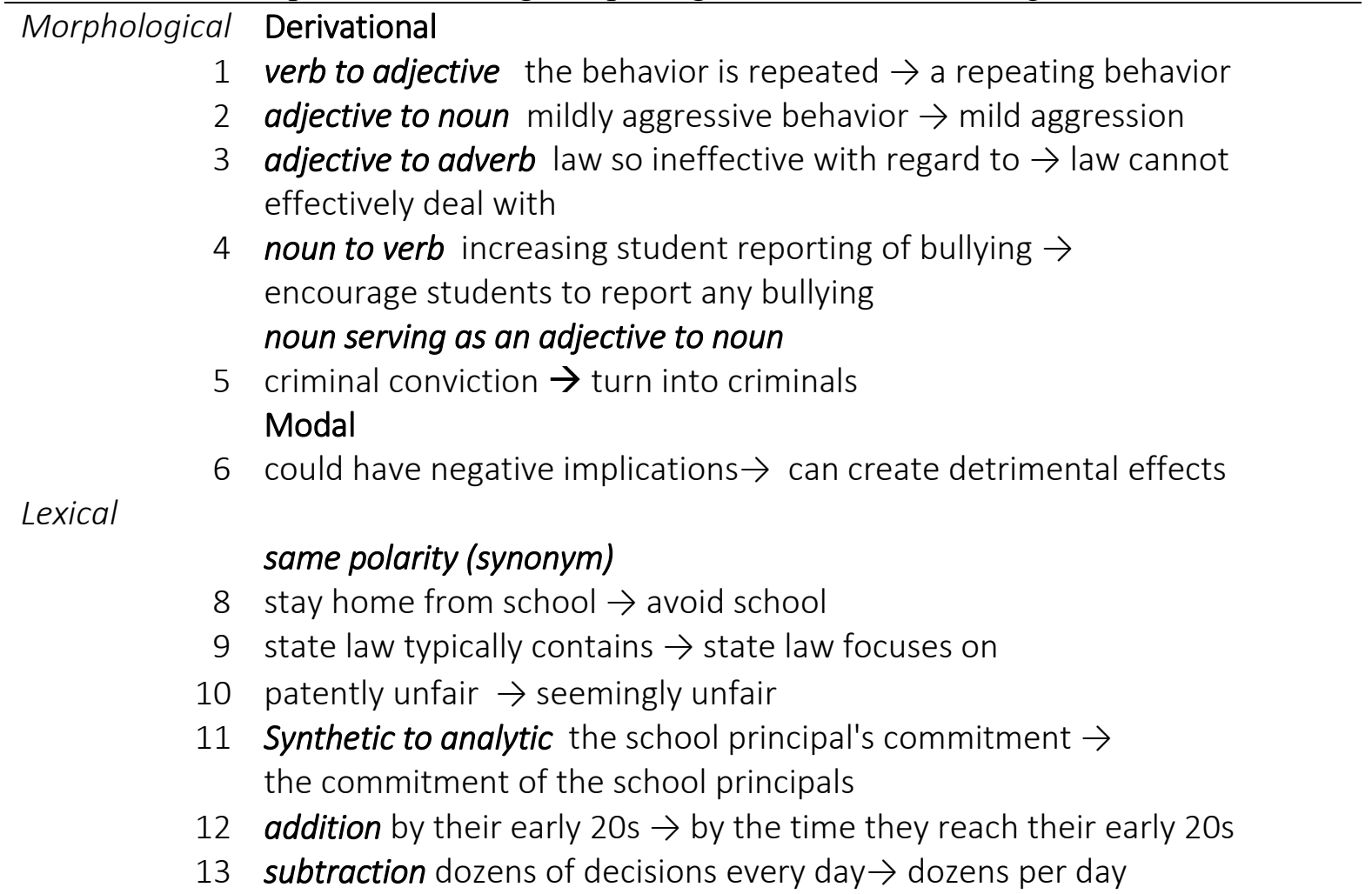

Table 2 Wes' Paraphrases Showing Syntactic Changes

Syntactic

diathesis (voice)

14 active to passive physical bullying includes $\rightarrow$ physical bullying is defined as

\section{embedding/subordination}

15 to adverb clause

It seems patently unfair to hold a teacher liable... $\rightarrow$...as it would be seemingly unfair to punish teachers ...

clause reordering 
16 Other bystanders frequently join in the bullying and begin to view the victims as somehow deserving of the treatment. The bullies themselves have a remarkably high probability of a criminal conviction by the time they reach their early 20 s. $\rightarrow$ Researches show that a high percentage of bullies turn into criminals by their early 20s, and bystanders may feel the same vulnerability and share the same effect on the victims (Weddle, 2003). 